\title{
Short- and long-term memories formed upon backward conditioning in honeybees (Apis mellifera)
}

\author{
Johannes Felsenberg, Jenny Aino Plath, Steven Lorang, Laura Morgenstern, \\ and Dorothea Eisenhardt ${ }^{1}$
}

Freie Universität Berlin, FB Biologie, Pharmazie, Chemie, Institut für Biologie, Neurobiologie, 14195 Berlin, Germany

\begin{abstract}
In classical conditioning, the temporal sequence of stimulus presentations is critical for the association between the conditioned stimulus (CS) and the unconditioned stimulus (US). In forward conditioning, the CS precedes the US and is learned as a predictor for the US. Thus it acquires properties to elicit a behavioral response, defined as excitatory properties. In backward conditioning, the US precedes the CS. The CS might be learned as a predictor for the cessation of the US acquiring inhibitory properties that inhibit a behavioral response. Interestingly, behavior after backward conditioning is controlled by both excitatory and inhibitory properties of the CS, but the underlying mechanisms determining which of these opposing properties control behavior upon retrieval is poorly understood. We performed conditioning experiments in the honeybee (Apis mellifera) to investigate the CS properties that control behavior at different time points after backward conditioning. The CS properties, as characterized by the retardation or enhancement of subsequent acquisition, were examined $30 \mathrm{~min}$ and $24 \mathrm{~h}$ after backward conditioning. We found that $30 \mathrm{~min}$ after backward conditioning, the CS acquired an inhibitory property during backward conditioning depending on the intertrial interval, the number of trials, and the odor used as the CS. One day after backward conditioning, we observed significant retardation of acquisition. In addition, we demonstrated an enhanced, generalized odor response in the backward conditioned group compared to untreated animals. These results indicate that two long-lasting opposing memories have been formed in parallel: one about the excitatory properties of the CS and one about the inhibitory properties of the CS.
\end{abstract}

Learning about the predictive relationship between a neutral stimulus and a meaningful stimulus like food or the presence of a predator is essential for an animal to adjust its behavior to an ever-changing environment. During classical conditioning, animals learn the relationship between two stimuli, namely the association between an initially neutral stimulus, the conditioned stimulus (CS), and a meaningful stimulus, the unconditioned stimulus (US). When the CS precedes the US, i.e., during forward conditioning, animals learn that the initially neutral CS predicts the occurrence of the US. Accordingly, the CS elicits a conditioned response (CR) that is rather similar to the unconditioned response to the US. Based on his observation that the CS elicits the CR, Pavlov (1927) suggested that the CS gains excitatory properties during classical conditioning, and that it is these properties that evoke the CR.

It is less clear what properties the CS acquires during backward conditioning when the sequence of stimulus presentations is reversed, i.e., when the onset of the US precedes the onset of the CS. If the US and the CS are still overlapping, as in forward conditioning, the CS might be associated with the occurrence of the US. Accordingly, the CS might acquire excitatory properties. However, because the CS onset precedes the US offset and the CS presentation is followed by a phase without US presentation, the CS might also be learned as a predictor for the cessation or absence of the US. Thus, the CS might also gain inhibitory properties during backward conditioning. Indeed, in several studies it has been demonstrated that the CS acquires either inhibitory properties or excitatory properties or both (Keith-Lucas and Guttman 1975; Heth 1976; Ayres et al. 1987; Williams et al. 1992; Cole

\footnotetext{
${ }^{1}$ Corresponding author

E-mail dorothea.eisenhardt@fu-berlin.de

Article is online at http://www.learnmem.org/cgi/doi/10.1101/lm.031765.113.
}

and Miller 1999; Urushihara 2004). But the reason for these inconsistent findings is still poorly understood. One possible explanation is the time point at which the CS properties are tested after backward conditioning. After forward conditioning, several memories are formed that differ in their stability (McGaugh 2000; Davis 2011; Menzel 2012). Most likely, memories of differing stability are also formed after backward conditioning. If the CS gains inhibitory and excitatory properties at the same time during backward conditioning, opposing memories might be formed. If these opposing memories differ in their stability, they might control retention at different time points after backward conditioning. This control of behavior by opposing memories at different time points after backward conditioning might explain the inconsistent findings on the CS properties acquired during backward conditioning.

Accordingly, the time span between backward conditioning and retention testing might be crucial for understanding the properties of the CS acquired during backward conditioning.

Here we test this hypothesis in harnessed honeybees (Apis mellifera). The honeybee is a well-known invertebrate model organism for learning and memory research (Menzel et al. 2006; Giurfa and Sandoz 2012; Matsumoto et al. 2012; Menzel 2012). Memory formation has been thoroughly characterized using an appetitive classical conditioning paradigm, the olfactory conditioning of the proboscis extension response (PER) (Bitterman et al. 1983). In honeybees, the stability of an appetitive olfactory memory formed after forward conditioning depends on the

(C) 2013 Felsenberg et al. This article is distributed exclusively by Cold Spring Harbor Laboratory Press for the first 12 months after the full-issue publication date (see http://learnmem.cshlp.org/site/misc/terms.xhtml). After 12 months, it is available under a Creative Commons License (AttributionNonCommercial 3.0 Unported), as described at http://creativecommons. org/licenses/by-nc/3.0/. 
number of trials: Stable long-term memories are formed after forward conditioning with three or more conditioning trials, whereas transient short-term memories are formed after only one conditioning trial (Wüstenberg et al. 1998; Friedrich et al. 2004).

Here we apply a retardation-of-acquisition assay in order to examine the inhibitory and excitatory properties of the CS after backward conditioning (Hammond 1968; Rescorla 1969; Papini and Bitterman 1993). This assay is based on the assumption that inhibitory and excitatory properties of a CS add up to acquisition and retention scores. Accordingly, forward conditioning with a CS that has previously acquired inhibitory properties results in retarded acquisition, whereas forward conditioning with a CS that has acquired excitatory properties results in enhanced acquisition.

\section{Results}

The CS gains inhibitory properties during one-trial backward conditioning depending on the interstimulus interval

We first asked about the properties of the CS that can already be observed after one backward conditioning trial. Hellstern et al. (1998) demonstrated that the CS acquires inhibitory properties after one backward conditioning trial with an interval between the onset of the US and the onset of the CS, i.e., an interstimulus interval (ISI) of $15 \mathrm{sec}$. In this situation, the US and CS presentations are not overlapping.

To test the validity of the retardation-of-acquisition assay we first examined the CS inhibitory properties after backward conditioning with an ISI of $15 \mathrm{sec}$ as already described by Hellstern et al. (1998). We examined two groups: The first group received one backward conditioning trial with an ISI of 15 sec $\left(\right.$ BW $\left._{\text {ISI15 }}\right)$ using clove oil as CS and the second group remained untreated and was kept in its storage box while the $\mathrm{BW}_{\mathrm{ISI15}}$ group underwent backward conditioning (Naive). Thirty minutes after conditioning both groups underwent two CS-US pairings, i.e., forward conditioning (Fig. 1A).

In the $\mathrm{BW}_{\mathrm{ISI15}}$ group, a significantly lower percentage of animals showed a response to the odor during forward conditioning compared to the Naive group (first forward trial: $\mathrm{BW}_{\mathrm{ISI} 15}$, $3 \%$, Naive, $9 \%$; second forward trial: $\mathrm{BW}_{\mathrm{ISI} 15}, 38 \%$, Naive, $58 \%$; repeated measurement analysis of variances (rmANOVA): Group, $F_{(1,131)}=6.42, P<0.05$; Group $\times$ Time, $\left.F_{(1,325)}=2.88, P=0.09\right)$ (Fig. 1B). Thus, we demonstrate retardation of acquisition by a single backward conditioning trial with an ISI of $15 \mathrm{sec}$. We conclude that the CS acquired inhibitory properties during backward conditioning when the US and CS presentations were not overlapping.

We next asked whether the CS also acquires inhibitory properties during backward conditioning with one trial with an ISI of $2 \mathrm{sec}$, i.e., when the US and CS presentations are overlapping.

We examined two groups of animals: The first group received one backward trial with an ISI of $2 \mathrm{sec}\left(\mathrm{BW}_{\mathrm{ISI}}\right)$ again using clove oil as CS, and the second group was untreated (Naive) and remained in its storage box while the $\mathrm{BW}_{\mathrm{ISI} 2}$ group underwent backward conditioning. Thirty minutes after conditioning both groups underwent forward conditioning with two trials (Fig. 1C).

During forward conditioning, animals of the $\mathrm{BW}_{\mathrm{ISI} 2}$ group did not respond significantly differently compared to the Naive group (first forward trial: $\mathrm{BW}_{\mathrm{ISI}}, 17 \%$, Naive, $5 \%$; second forward trial: $\mathrm{BW}_{\mathrm{ISI} 2}, 74 \%$, Naive, $65 \%$; rmANOVA: Group, $F_{(1,325)}=1.8$, $P>0.05$; Group $\times$ Time, $\left.F_{(1,325)}=0.92, P>0.05\right)$ (Fig. 1D).

From this result we conclude that during backward conditioning with a single backward conditioning trial and an ISI of 2 $\mathrm{sec}$, the CS gains neither inhibitory properties nor excitatory properties strong enough to control behavior.
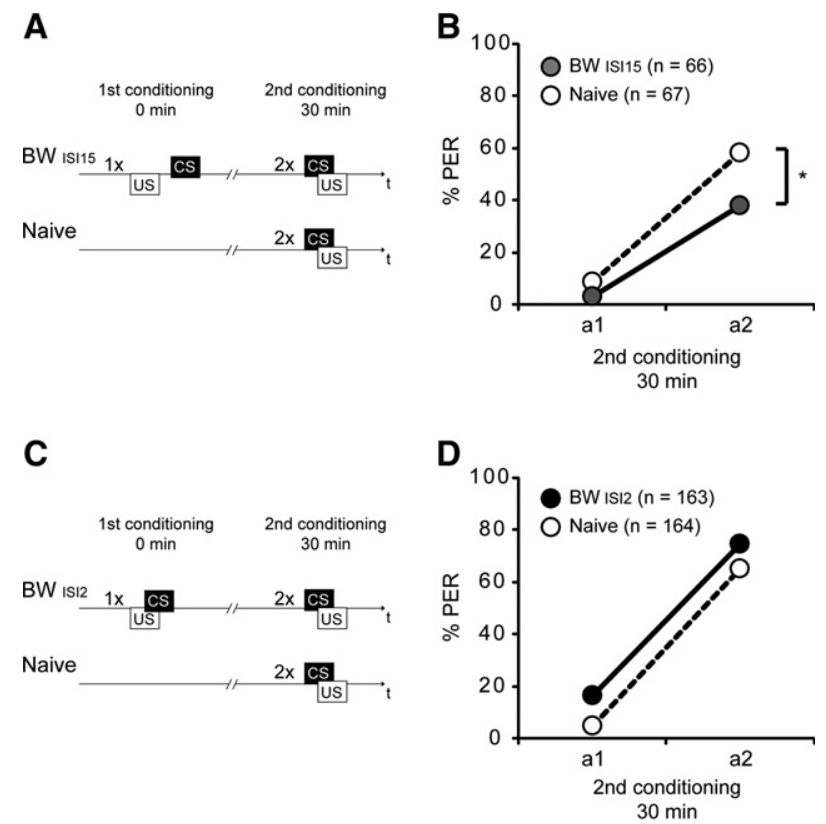

Figure 1. The CS gains inhibitory properties during one-trial backward conditioning depending on the interstimulus interval (ISI). (A) Schematic overview of the experiment using backward conditioning with an ISI of 15 sec. Honeybees were treated with one backward conditioning trial with an ISI of $15 \mathrm{sec}\left(\mathrm{BW}_{\mid \mathrm{SI} 15}\right)$ or were kept untreated (Naive). (B) Thirty minutes later the BW $\mathrm{BW}_{1 \mathrm{~S} 15}$ group (gray) and the Naive group (white) were conditioned with two forward conditioning trials (first acquisition trial a1 and second acquisition trial a2) using the same CS (clove oil) as in preceding backward conditioning. (C) Schematic overview of the experiment using backward conditioning with an ISI of $2 \mathrm{sec}$. Honeybees were treated with one backward trial with an ISI of $2 \mathrm{sec}\left(\mathrm{BW}_{1 S \mid 2}\right)$ or in parallel kept untreated (Naive). (D) Thirty minutes later the BW $\mathrm{BSI}_{2}$ group (black) and the Naive group (white) were conditioned with two forward trials (a1 and a2) using the same CS (clove oil) as in preceding backward conditioning. $(*) P<0.05$.

\section{Retardation of acquisition upon backward conditioning with three US-CS trials}

Next we investigated whether the number of trials compensates for the effect of the ISI on the acquisition of inhibitory properties. We examined three groups: The first group $\left(\mathrm{BW}_{\mathrm{ISI}}\right)$ received backward conditioning with three trials and an ITI of 2 sec using clove oil as CS; the second group (Naive) was left untreated and remained in its storage box; and the third group $\left(\mathrm{CS}_{\text {only }}\right)$ received three CS trials without a US application to control for latent inhibition, i.e., an inhibitory effect of a repeated CS presentation (Lubow and Moore 1959). All groups received two forward conditioning trials $30 \mathrm{~min}$ after the treatment (Fig. 2A). A significantly lower percentage of animals responded to the odor in the $\mathrm{BW}_{\mathrm{ISI} 2}$ group compared to the Naive group and the $\mathrm{CS}_{\text {only }}$ group (Fig. $2 \mathrm{~B})$. The $\mathrm{CS}_{\text {only }}$ group did not perform significantly differently from the Naive group. The PER performances during the first forward conditioning trial were not different between the three groups. However, in the second trial a significantly lower percentage of animals of the $\mathrm{BW}_{\mathrm{ISI} 2}$ group showed an odor response compared to the $\mathrm{CS}_{\text {only }}$ and the Naive group (first forward trial: $\mathrm{BW}_{\text {ISI2, }}$ $8 \%$, Naive, $4 \% \mathrm{CS}_{\text {only, }} \% \%$; second forward trial: $\mathrm{BW}_{\text {ISI2 }}, 22 \%$, Naive, $79 \%$, $\mathrm{CS}_{\text {only }}, 67 \%$; rmANOVA: Group, $F_{(2,141)}=13.4, P<$ 0.05 ; post hoc, $P_{\mathrm{BW}}$ vs. Naive $<0.05, P_{\mathrm{BW}}$ vs. CSonly $<0.05, P_{\text {Naive vs. }}$ CSonly $>0.05$; Group $\times$ Time, $F_{(2,141)}=30.6, P<0.05$; post hoc, $P_{\mathrm{A} 2 \text { BW vs. A2 Naive }}<0.05, P_{\mathrm{A} 2 \text { BW vs. A2 CS only }}<0.05, P_{\mathrm{A} 2} \mathrm{CS}$ only vs. A2 Naive $>0.05$ ) (Fig. 2). 
A

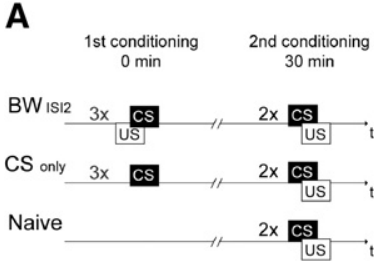

C

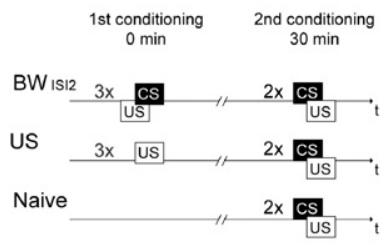

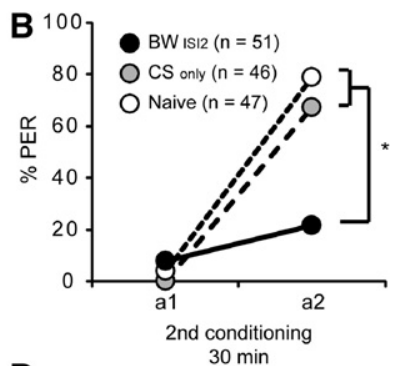

D

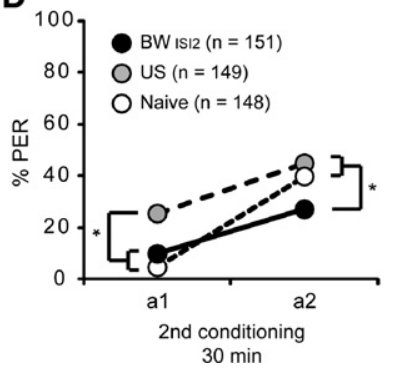

Figure 2. Retardation of acquisition upon backward conditioning. (A) Schematic overview of the experiment using three backward trials with an ISI of $2 \mathrm{sec}$ or three CS only trials. Honeybees were treated with three backward trials $\left(\mathrm{BW}_{\mathrm{ISI}}\right)$ or three CS trials alone (CSonly), or were untreated (Naive). (B) Thirty minutes later the BW ${ }_{1 S 12}$ group (black), the CSonly group (gray), and the Naive group (white) were conditioned with two forward trials (first acquisition trial a1 and second acquisition trial a2) using the same CS (clove oil) as in backward conditioning. (C) Schematic overview of the experiment using three-trial US pre-exposure or three backward trials with an ISI of $2 \mathrm{sec}$. Honeybees were treated with three US trials (US), with three backward trials $\left(\mathrm{BW}_{1 S \mathrm{I} I 2}\right)$, or were left untreated (Naive). (D) Thirty minutes later the US group (gray), the $\mathrm{BW}_{\mathrm{ISI} 2}$ group (black), and the Naive group (white) were conditioned with two forward trials (a1 and a2) using the same CS (clove oil) as in backward conditioning. $\left(^{*}\right) P<0.05$.

These results showed that backward conditioning with three US-CS trials retards acquisition. We excluded the possibility that the CS alone accounts for this effect.

However, it has been described previously that repeated preexposure to the US can retard subsequent acquisition (Siegel and Domjan 1971). Thus, in a second experiment we tested whether the US alone accounts for the retardation of acquisition observed after backward conditioning. We examined three groups: The first group ( $\mathrm{BW}_{\text {ISI2) }}$ ) received backward conditioning with three trials and an ITI of 2 sec with clove oil as CS, the second group received three US trials (US), and the third group was left untreated (Naive) and remained in its storage box. The three groups were subjected to two forward conditioning trials $30 \mathrm{~min}$ later to test for retardation of acquisition due to the US presentation alone (Fig. 2C). At the first acquisition trial the percentage of animals in the US group showing a PER during odor presentation was significantly higher than in the Naive group and in the $\mathrm{BW}_{\mathrm{ISI}}$ group. At the second acquisition trial the percentage of animals showing a PER was similar in the US group and the Naive group, but both groups were significantly different from the percentage of PER in the $\mathrm{BW}_{\text {ISI2 }}$ group (first forward trial: US, $26 \%$, Naive, $5 \%$, $\mathrm{BW}_{\text {ISI2 }}, 10 \%$; second forward trial: US, 45\%, Naive, 40\%, $\mathrm{BW}_{\mathrm{ISI} 2}, 27 \%$; rmANOVA: Group, $F_{(2,373)}=9.5, P<0.05$; post hoc, $P_{\mathrm{US}}$ vs. BW $<0.05, P_{\mathrm{US}}$ vs. Naive $<0.05, P_{\mathrm{BW}}$ vs. Naive $>0.05$, Group $\times$ Time, $F_{(2,373)}=8.3$, $P<0.05$; post hoc, $P_{\mathrm{A} 1}$ us vs. A1 Naive $<0.05, P_{\mathrm{A} 1}$ Us vs. A1 BW $<$ $0.05, P_{\mathrm{A} 1}$ BW vs. A1 Naive $>0.05, P_{\mathrm{A} 2}$ Us vs. A2 Naive $>0.05, P_{\mathrm{A} 2}$ Us vs. A2 BW $<0.05, P_{\mathrm{A} 2}$ BW vs. A2 Naive $\left.<0.05\right)$ (Fig. $2 \mathrm{D}$ ).

Taken together, three US trials do not decrease the PER throughout subsequent forward conditioning compared to the

untreated group. Instead we find that the US increases the PER at the first forward trial compared to the untreated control, but not at the second trial. In addition, we again demonstrate that the $\mathrm{BW}_{\text {ISI2 }}$ group shows a retardation of acquisition. This suggests that the US presentation alone does not result in a retardation of acquisition. However, this finding must be interpreted with caution because the difference between the US group and the Naive group that we demonstrated in the first conditioning trial is not visible at the second trial. This lack of difference between the US group and the untreated group could be interpreted as retardation of acquisition in the US group.

\section{The CS gains inhibitory properties during backward conditioning with three US-CS trials depending on the odor used as CS}

From the previous experiment, we could not entirely exclude that repeated US presentations might retard subsequent forward acquisition. If the repeated US presentation during backward conditioning accounted for a retardation of acquisition rather than the inhibitory properties of the CS, the retardation of acquisition should not be odor specific. To test this hypothesis we investigated whether the retardation of acquisition observed after backward conditioning with three US-CS trials is specific to the CS, in our case odor specific. We first tested whether bees are able to discriminate between the two odors that we used in subsequent experiments: clove oil and 1-hexanol. We trained bees with two forward conditioning trials using either clove oil or 1-hexanol odor as the CS. The bees were divided into two groups 30 min later. One group was tested with the conditioned odor (Same) and the other with the second, different odor (Different) (Fig. 3AD). Significantly fewer animals responded to the different odor compared to the previously trained odor. This result holds true regardless of whether clove oil (Same, 88\%, Different, 66\%; $G$ test: $G=5.46, P<0.05$ ) (Fig. 3A,B) or 1-hexanol (Same, 95\%, Different, $41 \%$; $G$ test: $G=28.60, P<0.05)$ was used as trained odor (Fig. 3C,D). This result demonstrates that bees distinguish between the two odors and form an odor-specific memory.

Next, we investigated whether retardation of acquisition after backward conditioning is odor specific. We examined three groups of bees: Two groups were conditioned with three backward trials using either clove oil (C) or 1-hexanol (H) and a third group was left untreated. Each of these three groups was divided into two groups $30 \mathrm{~min}$ after backward conditioning. To test for retardation of acquisition, all groups were trained with two forward conditioning trials using either the same odor as in the preceding backward conditioning or a different odor. The untreated group was always tested with a novel odor. This resulted in the following combinations of backward and forward conditioning: $\mathrm{C}-\mathrm{C}$ and $\mathrm{H}-\mathrm{H}$ (Same), $\mathrm{C}-\mathrm{H}$ and H-C (Different), and in case of the untreated groups $\mathrm{H}$ or $\mathrm{C}$ (Naive). When clove oil was used during backward conditioning and in the untreated group $(\mathrm{C}-\mathrm{C}, \mathrm{C}-\mathrm{H}, \mathrm{C})$ no difference between the Same, Different, and Naive group was observed in the first forward trial (first forward trial: Same, 9\%, Different, $19 \%$, Naive, $4 \%$; rmANOVA: Group, $F_{(2,245)}=8.3, P<$ 0.05 ; post hoc, $P_{\text {Same vs. Different }}<0.05, P_{\text {Same vs. Naive }}<0.05$, $P_{\text {Naive vs. Different }}>0.05$; Group $\times$ Time, $F_{(2,245)}=11.8, P<0.05$; post hoc, $P_{\mathrm{A} 1 \text { Same vs. Naive }}>0.05, P_{\mathrm{A} 1 \text { Naive vs. Different }}>0.05, P_{\mathrm{A} 1}$ Same vs. Different $>0.05$ ) (Fig. 3E,F). At the second forward trial animals from the Different group responded on a similar level as the Naive group. However, at the second trial both groups responded significantly more than animals trained with the same odor (second forward trial: Same, 26\%, Different, 54\%, Naive, 58\%; rmANOVA: Group $\times$ Time, $F_{(2,245)}=11.8, P<0.05$; post hoc, $P_{\mathrm{A} 2}$ Same vs. Naive $<0.05, P_{\mathrm{A} 2}$ Naive vs. Different $>0.05, P_{\mathrm{A} 2}$ Same vs. Different $<0.05$ ) (Fig. 3E,F). 
A

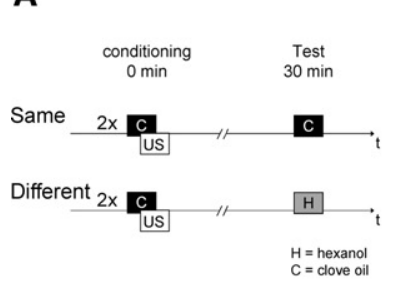

E

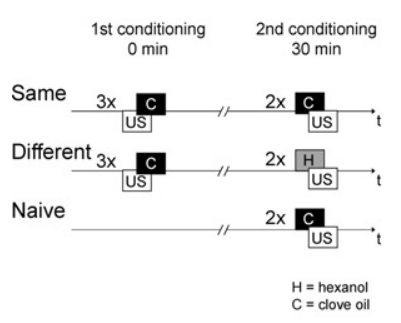

B

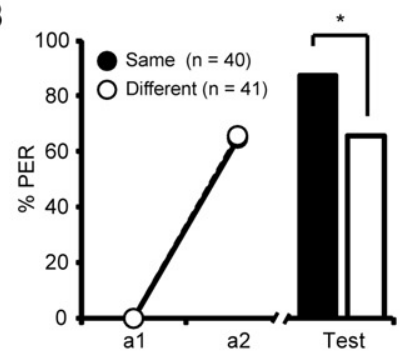

F

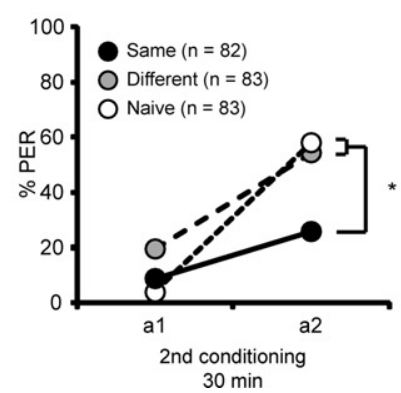

C

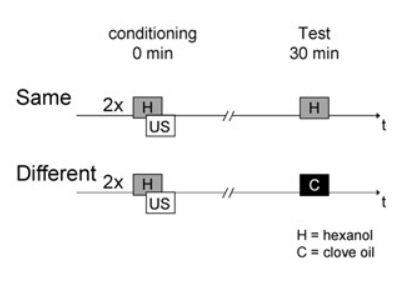

G

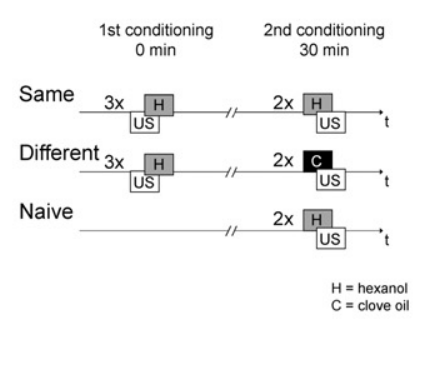

D

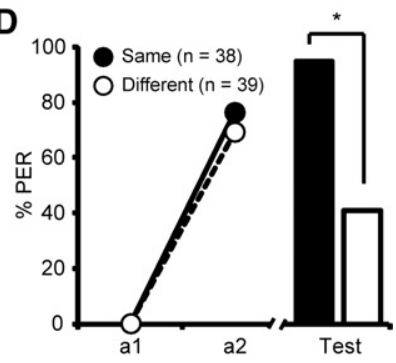

H

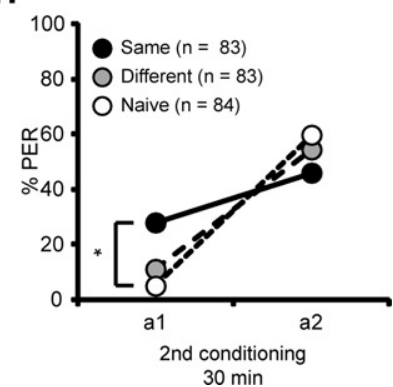

Figure 3. The retardation of acquisition is odor-specific. $(A-D)$ Schematic overview and the results of the experiments investigating odor specificity of memory retention after forward conditioning with clove oil $(A, B)$ or 1-hexanol $(C, D)$. $(B, D)$ Honeybees were conditioned with two forward conditioning trials (circles, first acquisition trial a1 and second acquisition trial a2). Thirty minutes later bees where tested (bars) either with the trained odor (black) or with a different odor (white). $\left(^{*}\right) P<0.05$. (E-G) Schematic overview and results of the experiments investigating odor specificity of memory retention after backward conditioning with clove oil $(E, F)$ or 1-hexanol $(G, H)$. $(F, H)$ Bees were treated with three backward conditioning trials or were kept untreated. Thirty minutes later the backward trained group was subdivided into two subgroups: One was forward trained with the same odor as in the backward conditioning (Same, black), one group was forward trained with a different odor as in the backward conditioning (Different, gray). The untreated animals were also conditioned with two forward trials (Naive, white). $\left(^{*}\right) P<0.05$.

When 1-hexanol was used in backward conditioning and in the untreated group $(\mathrm{H}-\mathrm{H}, \mathrm{H}-\mathrm{C}, \mathrm{H})$ a significant difference between the Same group and the Naive group was observed in the first acquisition trial. The Different group was not significantly different from either group (first forward trial: Same, 28\%, Different, $11 \%$, Naive 5\%; rmANOVA: Group, $F_{(2,247)}=0.5, P>$ 0.05 , Group $\times$ Time, $F_{(2,247)}=11.4, P<0.05$; post hoc, $P_{\mathrm{A} 1 \text { same }}$ vs. Naive $<0.05, P_{\mathrm{A} 1 \text { Naive vs. Different }}>0.05, P_{\mathrm{A} 1 \text { Same vs. Different }}>$ 0.05 ) (Fig. $3 \mathrm{G}, \mathrm{H}$ ). In the second acquisition trial odor responses were similar in all three groups (second forward trial: Same, $46 \%$, Different, $54 \%$, Naive, $60 \%$; Group $\times$ Time, $F_{(2,247)}=11.4$, $P<0.05$; post hoc, $P_{\mathrm{A} 2}$ Same vs. Naive $>0.05, P_{\mathrm{A} 2 \text { Naive vs. Different }}>$ $0.05, P_{\mathrm{A} 2}$ Same vs. Different $\left.>0.05\right)$.

Taken together, these results demonstrate that odors differ in their capability to acquire inhibitory properties during backward conditioning. Clove oil acquires specific inhibitory properties during backward conditioning, whereas hexanol does not. In contrast, backward conditioning with 1-hexanol increased the response to 1-hexanol $(\mathrm{H}-\mathrm{H})$ compared to the Naive group $(\mathrm{H})$. Thus, we show that retardation of acquisition is odor specific when clove oil is used as CS. This finding indicates that CS properties acquired during three-trial backward conditioning depend on the stimulus that is used as a CS during backward conditioning.

\section{The inhibitory properties of the CS are long-lasting}

To test whether the inhibitory properties of the CS are long-lasting we trained one group with three backward conditioning trials on the first day $\left(\mathrm{BW}_{\mathrm{ISI2}}\right)$ using again clove oil as the CS and kept a second, untreated (Naive) group in their storage box. On the following day, both groups underwent forward conditioning with two trials (Fig. 4A).
At the first acquisition trial the percentage of animals from the $\mathrm{BW}_{\mathrm{ISI} 2}$ group that responded to the CS was significantly higher compared to the Naive group. At the second acquisition trial the percentage of animals of the $\mathrm{BW}_{\mathrm{ISI} 2}$ group that responded to the CS was significantly lower compared to the Naive group (first forward conditioning trial: BW, 24\%, Naive 9\%; second forward conditioning trial: BW, 56\%, Naive, 67\%; rmANOVA: Group $\times$ Time, $F_{(1,375)}=23.7, P<0.05$; post hoc, $P_{\mathrm{A} 1 \text { BW vs. Naive }}<0.05, P_{\mathrm{A} 2 \mathrm{BW} \text { vs. }}$ Naive $<0.05$ ) (Fig. 4B).

Taken together, these results demonstrate that the inhibitory properties of the CS are long-lasting. In addition, we observed an increased response at the first acquisition trial. Thus, we hypothesize that the CS gained long-lasting excitatory properties in addition to the inhibitory properties already observed.
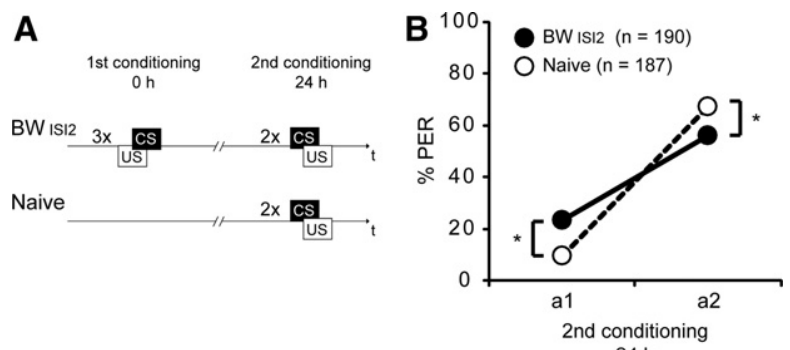

$24 \mathrm{~h}$

Figure 4. Inhibitory properties of the CS are long-lasting. (A) Schematic overview of the experiment. Bees were treated with three backward trials (BW ${ }_{1512}$ ) or were kept untreated (Naive). (B) Twenty-four hours later, bees from the BW $W_{1 S 12}$ group (black) and from the Naive group (white) were conditioned with two forward trials (first acquisition trial a1 and second acquisition trial a2) using the same CS (clove oil) as in backward conditioning. $(*) P<0.05$. 
The enhanced odor response $24 \mathrm{~h}$ after backward conditioning does not result from the US presentation alone

Next we asked whether the enhanced response to clove oil observed $24 \mathrm{~h}$ after backward conditioning is solely due to the presentation of the US alone, i.e., to a sensitization or the association of the context with the US. We tested whether three trials of US presentations result in a response rate comparable to that observed after backward conditioning.

We performed an experiment with three groups: One group received three US presentations alone (US), a second group was conditioned with three backward trials $\left(\mathrm{BW}_{\mathrm{ISI}}\right.$ ) again using clove oil as CS, and a third group remained untreated (Naive). Twentyfour hours later, the animals' response to the odor that had been used as the CS in the backward group was tested (Fig. 5A). The percentage of responding animals from the US group was significantly higher compared to the Naive group (Fig. 5B) (US $=38 \%$, Naive $=8 \%, \quad \mathrm{BW}_{\mathrm{ISI}}=19 \% ; G$ test: $G_{\mathrm{US}}$ vs. Naive $=39.39, P<$ 0.01). The percentage of animals from the BW group responding to the CS was significantly higher than that of the Naive group but significantly lower than that of the US group ( $G$ test: $G_{\text {Naive }}$ vs. $\mathrm{BW}=8.30, P<0.01 ; G_{\mathrm{US}}$ vs. $\mathrm{BW}=11.06, P<0.01$ ) (Fig. 5).

Taken together, we demonstrate that three trials of US presentations lead to a higher response to clove oil than three backward trials. We conclude that the response to clove oil after backward conditioning is not due to the US presentation alone. Rather, this enhanced response to clove oil observed $24 \mathrm{~h}$ after backward conditioning is due to the presentation of both stimuli, i.e., the US and the CS.

\section{A generalized odor response $24 \mathrm{~h}$ after backward conditioning}

Next we asked whether the enhanced response to the CS $24 \mathrm{~h}$ after backward conditioning is odor specific. We conditioned two groups of animals with three backward trials with an ISI of $2 \mathrm{sec}$ (BW ISI2) using either clove oil (C) or 1-hexanol (H) as CS. A third group remained untreated (Naive). Twenty-four hours later we divided each group into two groups which were tested for memory retention with either the same odor or the different odor or, in case of the Naive group, a novel odor. This resulted in the following combinations of backward conditioning and memory retention test: $\mathrm{C}-\mathrm{C}$ and $\mathrm{H}-\mathrm{H}$ (Same), $\mathrm{C}-\mathrm{H}$ and $\mathrm{H}-\mathrm{C}$ (Different), and in case of the Naive group in testing animals with clove oil or 1-hexanol. The percentage of backward conditioned bees responding to the same and the different odor in the test was not significantly different (clove oil: Same, 39\%, Different, 39\%; $G$ Test: $G=0.01, P>0.05$ [Fig. 6A,B]; 1-hexanol: Same, 47\%,
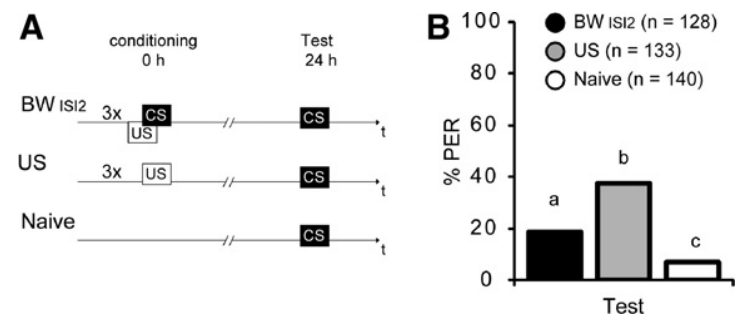

Figure 5. A US presentation alone does not account for the enhanced odor response $24 \mathrm{~h}$ after backward conditioning. (A) Schematic overview of the experiment. Honeybees were either treated with three backward conditioning trials (BW), exposed to three US trials (US), or were left untreated (Naive). (B) Twenty-four hours later the PER was tested with a CS (clove oil) presentation in all groups (BW, black; US, gray; Naive, white). Bars with unequal letters $(a-c)$ differ significantly $(P<0.01)$.
Different, 53\%; $G$ Test: $G=0.80, P>0.05$ [Fig. 6C,D]). But the difference of both groups of backward conditioned animals and the Naive group was significant disregarding which odor was used ( $G$ Test: clove oil, $G_{\text {backward Same vs. Naive }}=11.21, P<0.001$, $G_{\text {backward Different vs. Naive }}=12.27, P<0.001$; hexanol, $G_{\text {backward }}$ Same vs. NaiveT $=37.67, P<0.001, G_{\text {backward }}$ Different vs. Naive $=$ 48.89, $P<0.001)$.

Taken together, these results showed for clove oil and 1-hexanol an increased odor response $24 \mathrm{~h}$ upon backward conditioning. This increased odor response might result from a weak CSUS association. However, animals respond to the backward conditioned odor and a novel odor to the same extent suggesting that $24 \mathrm{~h}$ upon backward conditioning the odor response is generalized. Upon generalization animals respond to a novel stimulus in the same way as to a previously learned, perceptually distinct stimulus (Shepard 1987; Ghirlanda and Enquist 2003).

Next we ask whether the similar odor response to the backward conditioned odor and a different odor is due to generalization or results from a general failure of the animals to differentiate the conditioned odor from the different odor $24 \mathrm{~h}$ upon forward conditioning.

We conditioned animals with three forward trials (FW) with an ITI of 10 min using either clove oil (C) or 1-hexanol (H) as CS. Twenty-four hours later we divided each group into two groups that were tested with clove oil or with 1-hexanol.

The percentage of forward conditioned animals responding to the same odor $(\mathrm{C}-\mathrm{C}, \mathrm{H}-\mathrm{H})$ was significantly higher compared to animals responding to the different odor $(\mathrm{C}-\mathrm{H}, \mathrm{H}-\mathrm{C}$ ) (clove oil: Same, 94\%, Different, 39\%; $G$ Test: $G=63.01, P<0.05$ [Fig. 6E,F]; hexanol: Same, 84\%, Different, 56\%; $G$ Test: $G=17.14$, $P<0.05$ [Fig. 6G,H]). These results demonstrate that forward training results in odor specific memories $24 \mathrm{~h}$ upon conditioning. Thus, $24 \mathrm{~h}$ after forward conditioning the animals are still able to differentiate between the conditioned (same) and a different odor. We conclude that the similar responses to the conditioned odor and a different odor $24 \mathrm{~h}$ after backward conditioning are not due to the inability of the animals to differentiate between both odors. Instead, animals generalize the different odor to the backward conditioned odor as a consequence of backward conditioning.

\section{Discussion}

\section{Short-lasting inhibitory properties of the CS depend on the number of trials during backward conditioning and the odor used as CS}

We here investigated the CS properties that control behavior at different time points after backward conditioning. First, we demonstrated that the formation of a short-term memory about the inhibitory properties of the CS depends on the ISI, the number of backward conditioning trials, and the odor used as CS.

We observed a retardation of acquisition when we presented one backward trial with an ISI of $15 \mathrm{sec}$. A similar result was reported by Hellstern et al. (1998) using clove oil as CS. They demonstrated in honeybees that the ISI of US and CS is critical for the establishment of short-lasting inhibitory properties of the CS after one backward conditioning trial. In their study, an ISI of $15 \mathrm{sec}$ was optimal for the CS to acquire inhibitory properties already during one backward conditioning trial, whereas shorter ISI (6 sec) or longer ISI $(300 \mathrm{sec})$ were not sufficient for the CS to acquire inhibitory properties during one trial (Hellstern et al. 1998). In contrast, here we demonstrate that the CS acquires inhibitory properties during backward conditioning with an ISI of $2 \mathrm{sec}$, but only when three backward trials were presented. A stimulus presentation with an ISI of 2 sec means that the US and CS 
A

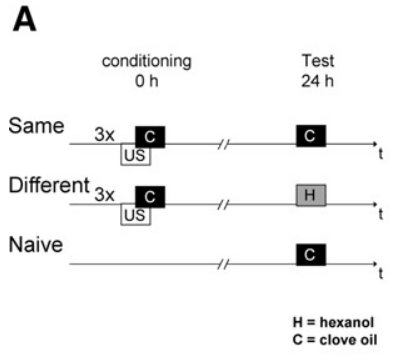

E

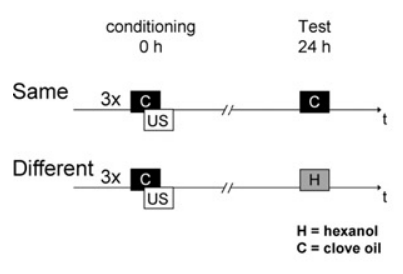

B

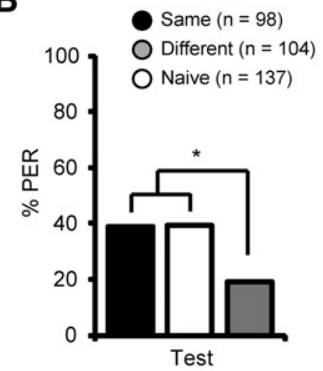

F

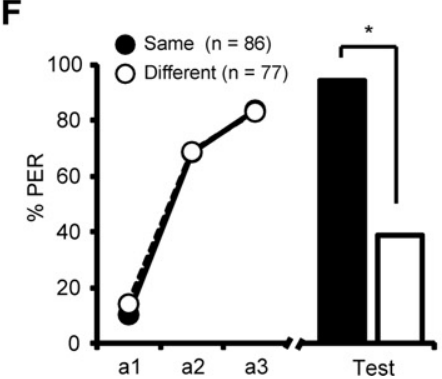

C

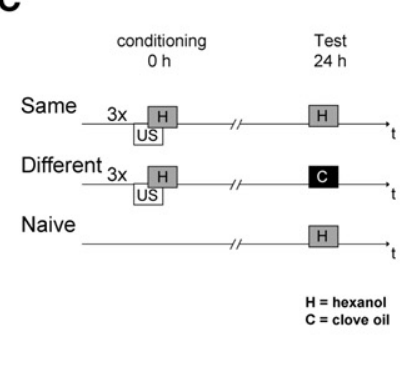

G

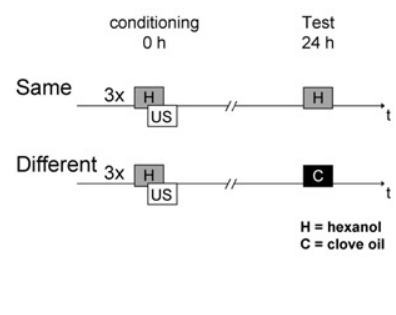

D

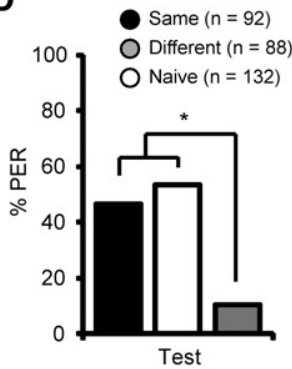

H

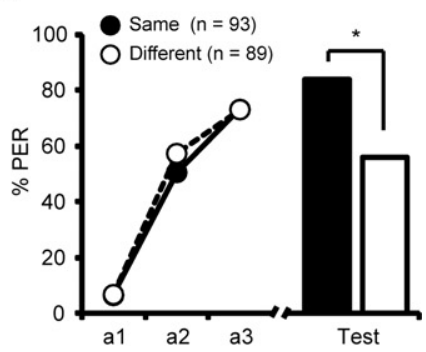

Figure 6. Enhanced, but generalized odor response $24 \mathrm{~h}$ after backward conditioning. $(A-D)$ Schematic overview and results of the experiments investigating odor specificity of memory retention $24 \mathrm{~h}$ after backward conditioning with clove oil $(C)$ or 1 -hexanol $(H)$. $(B, D)$ Honeybees were either backward conditioned (BW $\mathrm{BWI}_{12}$ ) or were left untreated (Naive). Twenty-four hours later the backward trained group was subdivided into two subgroups: One was tested with the same odor as in the backward conditioning (Same, black), one group was tested with a different odor as in the backward conditioning (Different, gray). In parallel, the odor responses of untreated animals were tested (Naive, white). $\left({ }^{*}\right) P<0.001 .(E, H)$ Schematic overview and results of the experiments investigating odor specificity of memory retention after backward conditioning clove oil $(E, F)$ or 1 -hexanol $(G, H)$. $(F, H)$ Honeybees were conditioned with three forward conditioning trials (circles). Twenty-four hours later bees where tested (bars) either with the trained odor (black) or with a different odor (white). $\left(^{*}\right) P<0.05$.

presentations overlap by 2 sec. During backward conditioning with overlapping stimuli, the temporal contiguity of the two stimuli might result in an ambiguous meaning of the CS: first, the CS appears simultaneously with the US and therefore might be associated with the presence of the reward leading to excitatory properties for the CS and, second, the CS might be learned as a predictor for the cessation of the US leading to inhibitory properties for the CS. Thus, when the US and the CS presentations are overlapping animals might learn the precise temporal relation of US and CS only after several backward conditioning trials.

Interestingly, in dogs overlapping backward conditioning of an electric shock with a CS results in a weak inhibitory effect on a shock avoidance behavior compared to backward conditioning without any overlap of the US and the CS (Moscovitch and LoLordo 1968). Thus, the inhibitory properties of a CS acquired during overlapping backward conditioning (also termed cessation conditioning) are weaker than the inhibitory properties of a CS that has been backward conditioned without an overlapping US-CS presentation. Differences in the strength of the inhibitory properties acquired during overlapping vs. nonoverlapping backward conditioning might also be a reason for the necessity to repeat overlapping backward conditioning in honeybees in order to observe the inhibitory properties in behavior.

We demonstrated that besides the ISI and the number of trials, also the odor used as CS was critical for the inhibitory properties of the CS observed after $30 \mathrm{~min}$. Rescorla and Wagner (1972) proposed that a CS is characterized by a feature termed "salience" which determines the extent to which the CS is associated with a US. In honeybees it was demonstrated that the chemical structure (functional groups and carbon-chain length) is one feature that determines the salience of an olfactory stimulus (Guerrieri et al. 2005). The two olfactory stimuli used in this study differ in their chemical structure since 1-hexanol is a pure odorant whereas clove oil is an odor mixture. Up-to-date 1-hexanol has not been shown to be an ingredient of clove oil (Bhuiyan 2012; Hossain et al. 2012). Therefore, it seems likely that 1-hexanol and clove oil differ in their salience and that this difference is the reason for the different properties acquired during backward conditioning. Taken together we hypothesize that the salience of the CS is an important factor strengthening either the inhibitory or the excitatory association between CS and US during backward conditioning.

\section{Three-trial backward conditioning induces long-lasting inhibitory properties of the CS}

One day after backward conditioning, we observed significant retardation of acquisition again using clove oil as CS. In addition, we demonstrated an enhanced odor response in the backward conditioned group compared to untreated animals. This might indicate that two long-lasting opposing memories have been formed in parallel: one about the excitatory properties of the CS and one about the inhibitory properties of the CS.

This seems to be likely, because several authors have shown that the CS acquires excitatory and inhibitory properties at the same time (Tait and Saladin 1986; Williams et al. 1992; Droungas and LoLordo 1994; Barnet and Miller 1996). Barnet and Miller (1996), for example, demonstrated that a CS that acquired inhibitory properties during backward conditioning acts as a reinforcing stimulus during second-order conditioning. Thus, during the paired presentation of the previously backward-conditioned stimulus (CS1) and the second conditioned stimulus (CS2) the CS2 acquires excitatory properties. Barnet and Miller (1996) concluded that the CS1 is capable of activating a representation of the 
US, despite its previously acquired inhibitory properties. Thus, it also acquired excitatory properties during backward conditioning. In addition, Williams and Overmier (1988) demonstrated that the extinction of a backward trained CS results in a decrease of its excitatory properties thereby unmasking its inhibitory properties. Therefore, the authors assumed that a CS might have acquired excitatory properties and inhibitory properties at the same time.

Here we show that the enhanced response to the odor $24 \mathrm{~h}$ after backward conditioning is not restricted to the backward conditioned CS. Rather, it is also visible when a novel odor is presented. Therefore it is not entirely clear whether the CS acquired excitatory properties during backward conditioning. However, we excluded that the similar odor responses to the conditioned odor and the novel odor resemble a spontaneous reaction to odor presentation. In addition, we demonstrated that the odor response $24 \mathrm{~h}$ after backward conditioning is significantly lower than the odor response after presentation of the US alone. Thus, we conclude that backward conditioning does not solely reflect a memory formed about the US presentation alone, i.e., long-term sensitization or a context-US association. Nevertheless, we cannot exclude that the enhancement of response to an odor is caused by a US-dependent enhancement of response that adds up with the inhibitory properties of the CS during memory retention. However, we think that this scenario is rather unlikely because the responses to the CS and to a novel odor are the same $24 \mathrm{~h}$ after backward conditioning. If a US-dependent enhancement of the odor response adds up with the inhibitory properties of the CS we would expect a reduction of the odor response only when the CS is presented but not when a novel odor is applied.

Furthermore, we showed that the similar odor responses are not due to an inability of animals to distinguish the two odors $24 \mathrm{~h}$ upon forward conditioning but that animals generalize the different odor to the backward conditioned odor. Interestingly, experiments with pigeons demonstrated that the degree of generalization depends on the strength of the retrieved memory: More generalization can be observed when a weak associative memory is retrieved in comparison to a strong associative memory (Rescorla 2006). Therefore, it might well be that the generalized odor response we observe $24 \mathrm{~h}$ after backward conditioning is due to a rather weak association between the CS-US formed during backward conditioning. Thus, a weak excitatory association between the CS and the US could have been formed throughout backward conditioning.

\section{'Punishment learning' during backward conditioning with a rewarding US?}

Here we demonstrated that a CS acquires inhibitory properties during backward conditioning. Interestingly, in the fruit fly as well as in vertebrates, it has been suggested that backward conditioning of an aversive US results in a positive response toward the backward conditioned odor (Tanimoto et al. 2004; Yarali et al. 2008; Andreatta et al. 2010, 2012). This response was termed "relief-learning" (Tanimoto et al. 2004). Thus, backward conditioning with an aversive US results in a "reward-like behavioral effect" (Andreatta et al. 2010) that is elicited by the CS. Accordingly, by backward conditioning with an aversive US the CS apparently becomes a predictor for the cessation of the aversive US, and this cessation of the punishment is interpreted as being rewarding. The association of a CS with the cessation of the US might not only result in inhibitory properties of the CS but might reverse the value of the predicted situation: The failure of an aversive US is rewarding, thus the backward conditioned CS may predict a reward. The failure of a rewarding US may become aversive, in other words, a backward conditioned CS in an appetitive US situation may predict punishment. Do our results support this hypothesis? If the CS turns into a predictor for punishment, i.e., an aversive situation, we would expect withholding of the response when the CS is presented (Smith et al. 1991; Diegelmann et al. 2013). We observed withholding of the odor response $30 \mathrm{~min}$ after backward conditioning. Thus, it might well be that the CS is a predictor of an aversive situation.

However, in our experiments, depending on the olfactory stimulus, also an enhanced odor response was observed $30 \mathrm{~min}$ after backward conditioning. Moreover, $24 \mathrm{~h}$ after backward conditioning independently of the olfactory stimulus an enhanced generalized odor response was demonstrated. This might indicate that the CS predicts an aversive situation 30 min after backward conditioning with a rewarding US depending on the salience of the CS, but that this prediction of an aversive situation is not stable and can therefore no longer be observed $24 \mathrm{~h}$ after backward conditioning. Indeed, only short- and middle-term but not longterm memories $24 \mathrm{~h}$ after backward conditioning have been demonstrated upon relief-learning (Diegelmann et al. 2013). Accordingly, it might well be that during backward conditioning with a rewarding US "punishment learning" takes place depending on the salience of the CS (see above). This results in withholding of the response after backward conditioning. However, because we observe an enhanced odor response $24 \mathrm{~h}$ later, that is independent of the olfactory stimulus, this effect might not be long lasting.

Taken together, we demonstrate that during backward conditioning with overlapping US-CS presentations the CS acquires inhibitory properties that last for at least $24 \mathrm{~h}$ after conditioning. In addition, backward conditioning leads to enhanced generalized odor response $24 \mathrm{~h}$ but not $30 \mathrm{~min}$ after backward conditioning. We hypothesize that this effect is due to a weak CS-US association. However, if this holds true it remains to be clarified why this weak CS-US association is not visible shortly after backward conditioning. One explanation would be that the inhibitory properties of the CS are stronger $30 \mathrm{~min}$ after backward conditioning than $24 \mathrm{~h}$ after backward conditioning thereby masking the CS excitatory properties shortly after backward conditioning. Interestingly, our results indicate that the inhibitory properties of the CS depend on the CS salience. Therefore we assume that opposing memories of differing stability are formed upon backward conditioning that control behavior depending on the time point of retrieval and the salience of the CS.

\section{Materials and Methods}

\section{General procedures}

Honeybee hives were located at the Freie Universität Berlin. Forager bees were caught at the hive entrance when flying out. Catching, fixing, and feeding was done as described previously (Felsenberg et al. 2011). Experiments were carried out from March 2009 to October 2013.

\section{Behavioral procedures}

All experiments were performed in front of the inlet of an exhaust fan. At least 30 min before training, animals were moved out of the storage box and placed next to this experimental setup to acclimatize.

During conditioning or stimulus presentations consisting of more than one trial, an intertrial interval (ITI) of 2 min was used. The US consisted of a $1.25 \mathrm{M}$ sucrose solution. Syringes for odor application were loaded daily with $4 \mu \mathrm{L}$ clove oil from Eugenia caryophyllata (PZN 06860287, Bombastus-Werke AG) or $4 \mu \mathrm{L}$ 1-hexanol (Merck) pipetted on a round filter paper of $1 \mathrm{~cm}$ in diameter (MACHERY-NAGEL GmbH \& Co.). 


\section{Forward conditioning (FW)}

In one forward conditioning trial animals were put into the experimental setup and remained there for 10 sec before the CS was presented for $5 \mathrm{sec}$. Three seconds after odor onset the presentation of the US started and lasted $4 \mathrm{sec}$. After the US offset the animals remained in the experimental setup for another $11 \mathrm{sec}$. A bee scored positive when its proboscis crossed a virtual line between the open mandible tips during the first $3 \mathrm{sec}$ of the CS presentation.

\section{Backward conditioning with an ISI of 2 sec (BW ISI2)}

One backward conditioning trial consisted of $10 \mathrm{sec}$ placed in the experimental setup followed by 4-sec US presentation. Two seconds after the US onset, the presentation of the CS started and lasted for $5 \mathrm{sec}$. Accordingly, the time interval between the US onset and the CS onset (= interstimulus interval [ISI]) was $2 \mathrm{sec}$. After the CS offset the animal remained in the experimental setup for $11 \mathrm{sec}$ before being removed to the resting position.

\section{Backward conditioning with an ISI of $15 \mathrm{sec}\left(\mathrm{BW}_{\text {ISIIS }}\right)$}

One backward conditioning trial consisted of $10 \mathrm{sec}$ placed in the experimental setup followed by a 4 -sec US presentation. Fifteen seconds after the US onset, the presentation of the CS started and lasted for $5 \mathrm{sec}$. Accordingly, the time between the US onset and the CS onset (ISI) was 15 sec. After the CS offset the animal remained in the experimental setup for $11 \mathrm{sec}$ before being removed to the resting position.

\section{US presentation}

A US trial consisted of $10 \mathrm{sec}$ placed in the experimental setup followed by a 4 -sec US presentation. Bees remained in the experimental position for another $14 \mathrm{sec}$.

\section{CS-only presentation}

A CS trial consisted of $10 \mathrm{sec}$ placed in the experimental setup followed by a 5-sec CS presentation. The animals remained in the experimental position for another $13 \mathrm{sec}$.

\section{Untreated animals}

Untreated animals (Naive) remained in the storage box during the entire conditioning procedure, but were otherwise handled in the same way as the groups described above.

\section{Data analysis and statistics}

Only data from animals which survived the entire experiment, responded to all US stimulations during the experiment, and to a final US presentation were analyzed. The $G$ Test for contingency tables (log likelihood ratio for contingency tables [Zar 1984]) was used to test for significant differences between the percentages of CR of the different groups in a single test. Significance levels were Bonferonni-corrected when groups were tested more than once. A repeated measurement analysis of variances (rmANOVA) was used to analyze effects over multiple trials. Fisher's LSD test was used as a post hoc test when two groups were compared. If multiple groups were tested, Tukey's HSD test was used.

\section{Acknowledgments}

We thank Ayse Yarali and Randolf Menzel for comments on an earlier version of the manuscript. This study was supported through grant 01GQ0941 to D.E. from the German 366 Federal Ministry of Education and Research (BMBF) within the Bernstein Focus Neuronal Basis of Learning and through grant EI 512/2-1 to D.E. from the Deutsche Forschungsgemeinschaft (DFG) within the joint project FOR 1363 Biogenic Amines in Insects: Coordination of Physiological Processes and Behaviour.

\section{References}

Andreatta M, Muhlberger A, Yarali A, Gerber B, Pauli P. 2010. A rift between implicit and explicit conditioned valence in human pain relief learning. Proc Biol Sci 277: 2411-2416.

Andreatta M, Fendt M, Muhlberger A, Wieser MJ, Imobersteg S, Yarali A, Gerber B, Pauli P. 2012. Onset and offset of aversive events establish distinct memories requiring fear and reward networks. Learn Mem 19: $518-526$.

Ayres J, Haddad C, Albert M. 1987. One-trial excitatory backward conditioning as assessed by conditioned suppression of licking in rats: Concurrent observations of lick suppression and defensive behaviors. Learn Behav 15: 212-217.

Barnet RC, Miller RR. 1996. Second-order excitation mediated by a backward conditioned inhibitor. J Exp Psychol Anim Behav Process 22: 279-296.

Bhuiyan MNI. 2012. Constituents of the essential oil from leaves and buds of clove (Syzigium caryophyllatum (L.) Alston). Afr J Pharm Pharmacol 6: 1260-1263.

Bitterman ME, Menzel R, Fietz A, Schafer S. 1983. Classical conditioning of proboscis extension in honeybees (Apis mellifera). J Comp Psychol 97: $107-119$.

Cole RP, Miller RR. 1999. Conditioned excitation and conditioned inhibition acquired through backward conditioning. Learn Motiv 30: $129-156$.

Davis RL. 2011. Traces of Drosophila memory. Neuron 70: 8-19.

Diegelmann S, Preuschoff S, Appel M, Niewalda T, Gerber B, Yarali A. 2013 Memory decay and susceptibility to amnesia dissociate punishmentfrom relief-learning. Biol Lett 9: 20121171.

Droungas A, LoLordo VM. 1994. Evidence for simultaneous excitatory and inhibitory associations in the explicitly unpaired procedure. Learn Motiv 25: 1-25.

Felsenberg J, Gehring KB, Antemann V, Eisenhardt D. 2011. Behavioural pharmacology in classical conditioning of the proboscis extension response in honeybees (Apis mellifera). J Vis Exp.

Friedrich A, Thomas U, Muller U. 2004. Learning at different satiation levels reveals parallel functions for the cAMP-protein kinase A cascade in formation of long-term memory. J Neurosci 24: 4460-4468.

Ghirlanda S, Enquist M. 2003. A century of generalization. Anim Behav 66: $15-36$.

Giurfa M, Sandoz JC. 2012. Invertebrate learning and memory: Fifty years of olfactory conditioning of the proboscis extension response in honeybees. Learn Mem 19: 54-66.

Guerrieri F, Schubert M, Sandoz JC, Giurfa M. 2005. Perceptual and neural olfactory similarity in honeybees. PLoS Biol 3: e60.

Hammond LJ. 1968. Retardation of fear acquisition by a previously inhibitory CS. J Comp Physiol Psychol 66: 756-759.

Hellstern F, Malaka R, Hammer M. 1998. Backward inhibitory learning in honeybees: A behavioral analysis of reinforcement processing. Learn Mem 4: 429-444.

Heth CD. 1976. Simultaneous and backward fear conditioning as a function of number of CS-UCS pairings. J Exp Psychol Anim Behav Process 2: 117-129.

Hossain MA, Al-Hashmi RA, Weli AM, Al-Riyami Q, Al-Sabahib JN. 2012. Constituents of the essential oil from different brands of Syzigium caryophyllatum L by gas chromatography-mass spectrometry. Asian Pac J Trop Biomed 2: S1446-S1449.

Keith-Lucas T, Guttman N. 1975. Robust-single-trial delayed backward conditioning. J Comp Physiol Psychol 88: 468-476.

Lubow RE, Moore AU. 1959. Latent inhibition: The effect of nonreinforced pre-exposure to the conditional stimulus. J Comp Physiol Psychol 52: $415-419$.

Matsumoto Y, Menzel R, Sandoz JC, Giurfa M. 2012. Revisiting olfactory classical conditioning of the proboscis extension response in honey bees: A step toward standardized procedures. J Neurosci Methods 211: $159-167$.

McGaugh JL. 2000. Memory-a century of consolidation. Science 287: $248-251$.

Menzel R. 2012. The honeybee as a model for understanding the basis of cognition. Nat Rev Neurosci 13: 758-768.

Menzel R, Leboulle G, Eisenhardt D. 2006. Small brains, bright minds. Cell 124: $237-239$.

Moscovitch A, LoLordo VM. 1968. Role of safety in the Pavlovian backward fear conditioning procedure. J Comp Physiol Psychol 66: 673-678.

Papini MR, Bitterman ME. 1993. The two-test strategy in the study of inhibitory conditioning. J Exp Psychol Anim Behav Process 19: 342-352.

Pavlov IP. 1927. Conditioned reflexes: An investigation of the physiological activity of the cerebral cortex. Oxford University Press, London.

Rescorla RA. 1969. Pavlovian conditioned inhibition. Psychol Bull 72: $77-94$.

Rescorla RA. 2006. Stimulus generalization of excitation and inhibition. QJ Exp Psychol (Hove) 59: 53-67. 
Rescorla RA, Wagner AR. 1972. A theory of Pavlovian conditioning: Variations in the effectiveness of reinforcement and nonreinforcement. Classical conditioning II: Current research and theory (ed. Black AH, Prokasy WF), pp. 64-99. Appleton-Century Crofts, New York.

Shepard R. 1987. Toward a universal law of generalization for psychological science. Science 237: 1317-1323.

Siegel S, Domjan M. 1971. Backward conditioning as an inhibitory procedure. Learn Motiv 2: 1-11.

Smith BH, Abramson CI, Tobin TR. 1991. Conditional withholding of proboscis extension in honeybees (Apis mellifera) during discriminative punishment. J Comp Psychol 105: 345-356.

Tait R, Saladin M. 1986. Concurrent development of excitatory and inhibitory associations during backward conditioning. Anim Learn Behav 14: 133-137.

Tanimoto H, Heisenberg M, Gerber B. 2004. Experimental psychology: Event timing turns punishment to reward. Nature 430: 983.
Urushihara K. 2004. Excitatory backward conditioning in an appetitive conditioned reinforcement preparation with rats. Behav Processes 67: $477-489$.

Williams DA, Overmier JB. 1988. Some types of conditioned inhibitors carry collateral excitatory associations. Learn Motiv 19: 345-368.

Williams DA, Overmier JB, LoLordo VM. 1992. A reevaluation of Rescorla's early dictums about Pavlovian conditioned inhibition. Psychol Bull 111: $275-290$.

Wüstenberg D, Gerber B, Menzel R. 1998. Long- but not medium-term retention of olfactory memories in honeybees is impaired by actinomycin D and anisomycin. Eur J Neurosci 10: 2742-2745.

Yarali A, Niewalda T, Chen YC, Tanimoto H, Duerrnagel S, Gerber B. 2008. 'Pain relief' learning in fruit flies. Anim Behav 76: 1173-1185.

Zar JH. 1984. Biostatistical analysis. Prentice-Hall, Englewood Cliffs, NJ.

Received May 7, 2013; accepted in revised form October 14, 2013. 


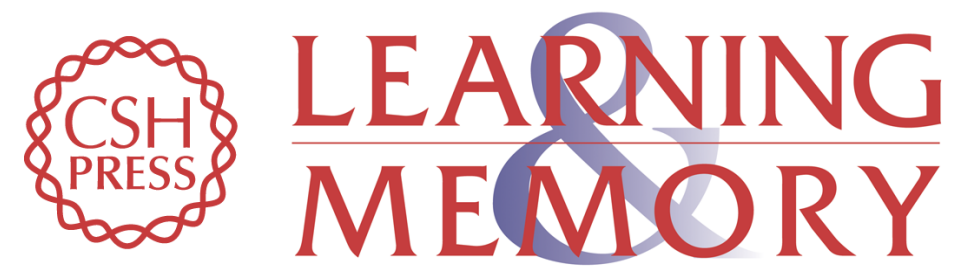

\section{Short- and long-term memories formed upon backward conditioning in honeybees ( Apis mellifera)}

Johannes Felsenberg, Jenny Aino Plath, Steven Lorang, et al.

Learn. Mem. 2014, 21:

Access the most recent version at doi:10.1101/Im.031765.113

References This article cites 38 articles, 6 of which can be accessed free at: http://learnmem.cshlp.org/content/21/1/37.full.html\#ref-list-1

Creative This article is distributed exclusively by Cold Spring Harbor Laboratory Press for the Commons License first 12 months after the full-issue publication date (see http://learnmem.cshlp.org/site/misc/terms.xhtml). After 12 months, it is available under a Creative Commons License (Attribution-NonCommercial 3.0 Unported), as described at http://creativecommons.org/licenses/by-nc/3.0/.

Email Alerting Receive free email alerts when new articles cite this article - sign up in the box at the Service top right corner of the article or click here. 